\title{
システム方程式の再構築による 気温時系列の予測について
}

Prediction of Temperature Time Series Using Reconstructed Chaotic System Equations

松本 実”, 神野 健二**, 河村 明"**, Ronny Berndtsson **** By Minoru MATSUMOTO, Kenji JINNO, Akira KAWAMURA, Ronny BERNDTSSON

\begin{abstract}
Prediction of long-term changes in temperature is of vital importance for estimation of future available water resources. An observed 238-year monthly temperature time series is investigated by chaos theory and use results from the analysis to make short-term predictions in real-time. We use the Lorenz equation as a reference system of equations and the extended Kalman filter to identify the structure of the governing system and make updated predictions. The results indicate that predictions can be made for filtered monthly temperature time series if the prediction lead time is short. Parts of monthly temperature variation at a point may follow a chaotic time trajectory as influenced by large-scale atmospheric flow.

Keywords: prediction, chaos theory, temperature, Lorenz equation
\end{abstract}

1.はじめに

近年の気候変動および異常気象の発生は，将来的な水資源確保の観点から不安定な要因として懸 念されている。そこで水文時系列の定量的予測と水資源への影響評価が重要な課題となっている。 現在, 全地球的な規模の気候変動評価は GCMs（大気循環モデル）等により試みられているが, 水 文・水資源で対象とする狭い地域での気候変動の予測とその評価をおこなうことは困難である。

ところで水文時系列は本来, 大気中の熱・物質・運動量輸送により生起し, 高次の非線形現象で

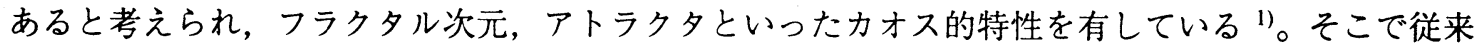
は確率論の範疇で取り扱われていた時系列を, 非線形力学系からの出力として捉え, その決定論的 規則性を利用し予測をおこなう研究が数多く見られるようになってきている ${ }^{2)}$ 。

本研究では，スウェーデン・ルンド市おいて 238 年間にわたり観測された月平均気温デー夕を用 い，その時系列に対してカオス理論を用いたシステム方程式の再構築と予測を試みる。その予測手 法は以下のようである ${ }^{3)}$ 。すなわち，(1)観測時系列からアトラクタを再構成し，次元を推定をする。 次に(2)時系列を支配する非線形力学系の存在を仮定し, Taylor 級数展開によりシステム方程式を再 構築する。そこで(3)再構築システム方程式を同定する際の参照システム方程式を導き, (4)拡張カル マンフィルタにより逐次パラメータを修正しながら時系列の予測をおこなう。

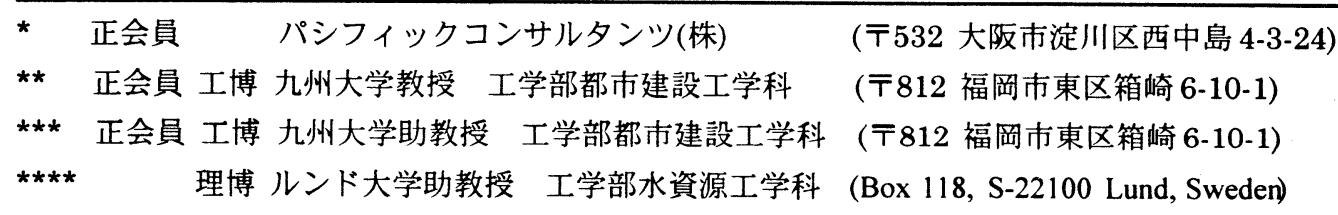




\section{2. 予測手法}

本研究における予測手法の概念を図-1に示す。まず前提として, 対象時系列を生成する決定論的 非線形力学系の存在を仮定する。一般的に真のシステム方程式を見つけることは不可能であり，そ こで我々は, 雑音の含まれた観測時系列から同等の時系列を生成しうるシステム方程式を再構築す ることになる。観測時系列に対してはまず雑音を取り除いた上で, Takens の埋め込み定理 ${ }^{4} に$ 基づ きアトラクタを再構成し, その次元を推定する。アトラクタの軌道は将来の変動が決して不規則な ものでなく，あるパターンをもってお り，それが予測可能であることを示し ている。再構成されたアトラクタの次 元 $d$ は, その時間波形を記述するのに 必要な変数の数を示しており,アトラ ク夕の次元 $d$ を求めることにより，も との時系列を支配するシステム方程 式の独立変数の数を決定することが できる ${ }^{5)}$ 。

さて再構築システム方程式の状態 変数の数を $n$ とし, $n$ 個の未知变数を ベクトルで, $X=\left[\begin{array}{lllll}x_{1} & x_{2} & x_{3} & \cdots & x_{n}\end{array}\right]^{\mathrm{T}} \quad\left({ }^{\mathrm{T}}:\right.$ 転 置)とすると, 一般的なシステム方程式 は次のように表せる。

$\dot{X}=F(X)$

つまり,

$\left\{\begin{array}{c}\dot{x}_{1}=f_{1}\left(x_{1}, x_{2} x_{3}, \cdots, x_{n}\right) \\ \dot{x}_{2}=f_{2}\left(x_{1}, x_{2} x_{3}, \cdots, x_{n}\right) \\ \vdots \\ \dot{x}_{n}=f_{n}\left(x_{1}, x_{2} x_{3}, \cdots, x_{n}\right)\end{array}\right.$

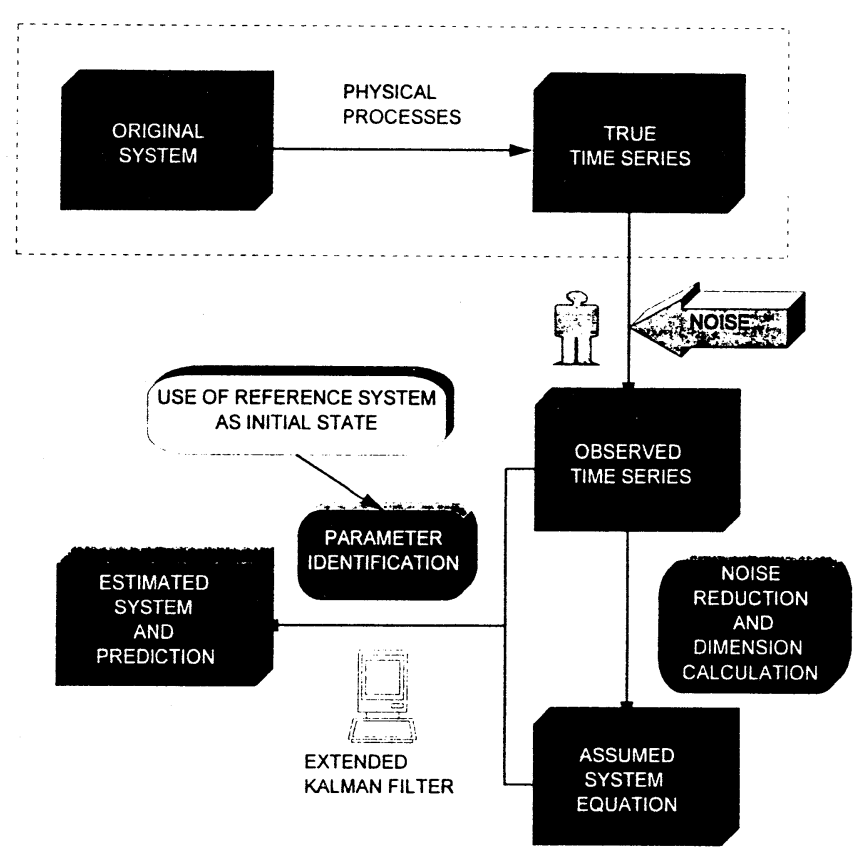

図-1 予測手法の概念

このシステムを決定するのに必要な情報は, 独立変数の数（フラクタル次元）および方程式の構造 である。本研究で対象とした気温時系列のアトラクタの次元 $d$ は, 相関次元 ${ }^{6)}$ 算定の結果およそ 2.5 であると推定されており ${ }^{7)}$, この場合 3 つの独立変数を含むシステム方程式からその時系列を生成 することができることを意味している。そこでシステム方程式を 3 つ独立变数 $x, y, z$ からなると すれば,一般的なシステム方程式として, 式(1)の関数 $F(X)$ を 2 次の項まで Taylor 級数展開した以下 の方程式が得られる。

$\left\{\begin{array}{l}\dot{x}=f_{1}(x, y, z)=a_{10}+a_{11} x+a_{12} y+a_{13} z+a_{14} x y+a_{15} y z+a_{16} x z+a_{17} x^{2}+a_{18} y^{2}+a_{1 y} z^{2} \\ \dot{y}=f_{2}(x, y, z)=a_{20}+a_{21} x+a_{22} y+a_{23} z+a_{24} x y+a_{25} y z+a_{26} x z+a_{27} x^{2}+a_{28} y^{2}+a_{2 y} z^{2} \\ \dot{z}=f_{3}(x, y, z)=a_{30}+a_{31} x+a_{32} y+a_{33} z+a_{34} x y+a_{35} y z+a_{36} x z+a_{37} x^{2}+a_{38} y^{2}+a_{34} z^{2}\end{array}\right.$

ここに $a_{i j}(i=1-3, j=0-9)$ はパラメータである。さてここで式(3)に対し観測時系列を入力として拡 張カルマンフィルターを適用し，パラメータの同定および時系列の予測をおこなう。しかしながら， ただ $1 つ の$ 観測時系列からこれら 30 個のパラメータを同定することは数值計算上非常に困難であ り, そのため未知パラメータの数を減らすなどのシステムの構造の単純化が必要となる。本研究で はパラメータ同定の際の初期条件として修正したLorenz 方程式を設定する。この理由と利点につい ては後述する。 


\section{3. 気温時系列のアトラクタ}

本研究で取り扱う月平均気温データ ${ }^{8}$ は 1741 年以来スウェーデン国南部のルンド市で観測され ているものであり，長期にわたりよく整備されている点で貴重なものである。

さて，本時系列に対し Schreiberにより紹介された非線形スムージング法 ${ }^{9}$ を適用した。このスム ージング法は, 非線形力学の分野で特に次元推定の理論から発展させたものであり, 単純なアルゴ リズムであるがカオス時系列ノイズ低減に極めて有効である。なおスペクトル解析の結果から, 月 平均気温の生デー夕は 1 年および 6 ケ月の卓越周期成分をもっており，これは地球の公転による影 響であるとみなし，スムージングは上記卓越 2 周期を取り除いた残差データについておこなった。 図-2には生データおよび非線形スムージング後の時系列について, 遅れ時間 $\tau$ を 2 月としたアト ラクタを示している。気温時系列のアトラクタは 2 つの周上を交互に行き来するような軌道をも っていることが分かる。

前述の通り, 本研究での予測手法では, 対象時系列のアトラクタと似た構造のアトラク夕をもつ システム方程式をに設定することで数值計算上の負荷を軽減する。Lorenz 方程式から模擬発生され た時系列 $x$ のアトラクタと気温時系列のアトラクタは非常に似た構造の軌跡をもつことから, 修正 された Lorenz 方程式を システム同定の際の初 期值として用いること が可能であると考えら れる。Lorenz 方程式 10) は熱駆動対流モデルか ら導かれたカオス方程 式であり，式(4)で示され る 3 元連立常微分方程 式である。

$$
\left\{\begin{array}{l}
\dot{x}=\sigma(y-x) \\
\dot{y}=R x-y-x z \\
\dot{z}=x y-b z
\end{array}\right.
$$

Cyclic component removed
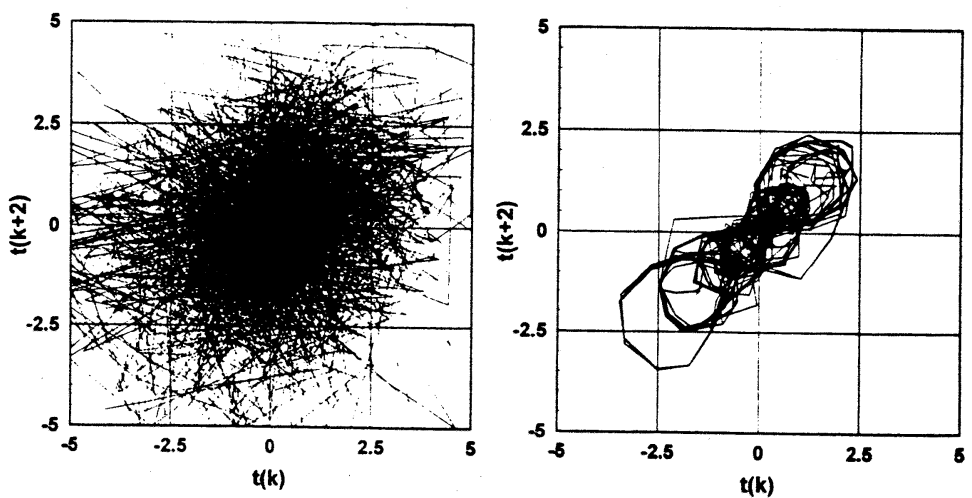

$\mathbf{t}(\mathbf{k})$

図-2 気温時系列のアトラクタ

ここに $\sigma, R, b$ はパラメータであり, 系の挙動に敏感に作用 する。この Lorenz 方程式を同定すべきシステムの初期条件と して用いるために線形変換を行う。すなわちノイズ低減され た気温時系列の振幅を合わせるために $x^{*}=\gamma x$, 周期を同調さ せるために $t^{*}=T t に$ にそれぞれ変換する。修正された Lorenz 方 程式は次のように表される。

$$
\left\{\begin{array}{l}
\frac{d x^{*}}{d t^{*}}=\frac{\sigma}{T}\left(y y-x^{*}\right) \\
\frac{d y}{d t^{*}}=\frac{1}{T}\left(\frac{R}{\gamma} x^{*}-y-\frac{1}{\gamma} x^{*} z\right) \\
\frac{d z}{d t^{*}}=\frac{1}{T}\left(\frac{1}{\gamma} x^{*} y-b z\right)
\end{array}\right.
$$

線形変換パラメータ $\gamma, T$ は気温時系列から求められ, この場

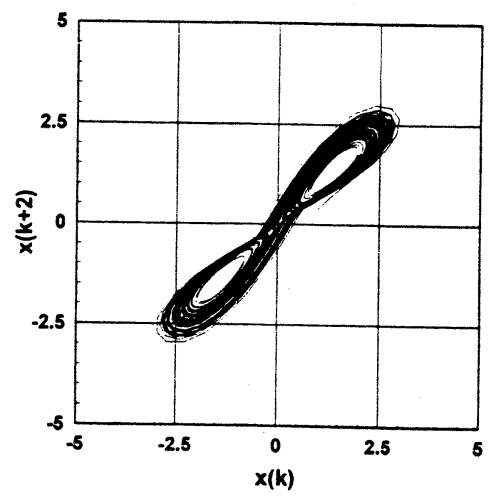

図-3 Lorenz 方程式のアトラク夕 合 $\gamma=0.20^{\circ} \mathrm{C}, T=0.13$ 月に設定する。

図-3に式(5)より発生させた時系列 $x$ について遅れ時間を $\tau=2$ とした位相空間上のプロットを示す。 気温時系列のアトラクタと比較すると，2つの円軌道をもっており，明らかな類似性が認められる。 


\section{4. 気温時系列の実時間予測}

パラメー夕同定の初期条件に は前述の通り線形変換した Lorenz 方程式(5)の各項の値を与 えた。すなわち, $a_{11}=-\sigma / T, a_{12}=$ $\sigma^{*} \gamma / T, a_{21}=R /\left(\gamma^{*} T\right), a_{22}=-1 / T$, $a_{26}=-1 /\left(\gamma^{*} T\right), a_{33}=-b / T, a_{34}=1 /(\gamma$ *T), そのほかのパラメータは 0 である。また観測時系列 $x$ に相当 する変数 $x_{1}$ の初期值は気温時系 列の初期値 0.356 に, その他の変 数 $x_{2}, x_{3}(=y . z)$ の初期値について は， $x_{2}, x_{3}$ ともに 10.0 を与えた。 以上の条件で, 気温時系列につ

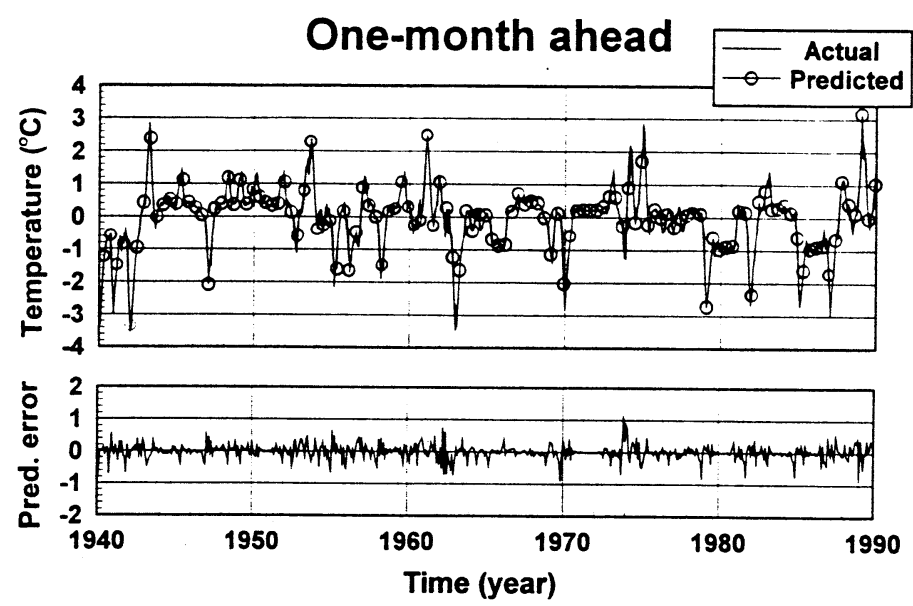

図-4 気温時系列の 1 ケ月先の予測

いて 1 ケ月先を予測した結果をその予測誤差とともに図-4に示す。1 月月先の予測は精度よくおこ なわれていることがわかる。それ以上の予測期間をとると誤差が大きく，精度は低くなった。予測 誤差が増大する理由は, 時間の経過とともに急速に元の情報を失うというカオス時系列の特性のた めであると考えられる。

\section{5. むすび}

本論文ではカオス理論を適用した気温時系列の予測手法を概説し，その適用結果を示した。月気 温データから周期成分を除いた残差時系列に対し, 少なくとも 1 ヶ月先の予測について精度良い結 果が得られた。さて, カオスカ学系は本質的に長期予測は不可能であるといわれているが10), 予測 のリードタイムは対象時系列の時間スケールに依存しており，それぞれの時間スケールには異なる アトラクタ（支配方程式）が存在しているものと考えられる。従って予測のリードタイムと予測精 度の関係については今後の検討が必要である。また気温時系列から再構築されたアトラクタは Lorenz 方程式のアトラクタとよく似ており, 熱駆動流体の理想化モデルから導かれた Lorenz 方程式 と大気の熱運動と密接に関わる気温時系列の物理的関連性は興味深い。

参考文献 1) 例えば, Rodoriguez-Iturbe, I., Febres de Power. B., Sharifi, M. B., Georgakakos, K. P., Chaos in rainfall, Water Resources Research, 25, 7, 1667-1675, 1989. 2) 例えば, Sugihara, G., and R. M. May, Nonlinear forecasting as a way of distinguishing chaos from measurement error in time series, Nature, 344, 734-741, 1990. 3) Jinno, K., S. Xu, R. Berndtsson, A. Kawamura, and M. Matsumoto, Prediction of sunspots using reconstructed chaotic system equations, J. Geophys. Res., 100, 14773-14781, 1995. 4) Takens, F., Detecting strange attractors in turbulance, In: Dynamical Systems and Turbulence (D. A. Rand, L. S. Young eds.), Springer-Verlag, 366-381, 1981. 5) Grassberger, P., and I. Procaccia, Characterzation of strange attractors, Phys. Rev. Lett., 50, 346-349, 1983. 6) Grassberger, P., An optimized box-assisted algolithm for flactal dimensions, Phys. Lett. A, 148, 63-68, 1990. 7) Berndtsson, R., K. Jinno, A. Kawamura, J. Olsson, and S. Xu, Dynamical systems theory applied to long-term temperature and precipitation time series, In: Trends in Hydrology (J. Menon ed.), 291-297, counc. Sci. Res. Intrgr., Trivandrum, India, 1994. 8) 河村明, 神野健二, R. Berndtsson, スウェーデン・ルンド市における 238 年間の気 温および降水時系列の長期的変動解析, 第 4 回水資源シンポジゥム前刷集, 769-774, 1992. 9) Schreiber, T., An extremely simple nonlinear noise reduction method, Phys. Rev. E. Stat. Physics, 47, 2401-2404, 1993. 10) Lorenz, E. N., Deterministic nonperiodic flow, J. Atmos. Sci., 20, 130-141, 1963. 